\title{
Hyperglycemia-induced diaphragm weakness is mediated by oxidative stress
}

\author{
Leigh A Callahan ${ }^{*+}$ and Gerald S Supinski ${ }^{\dagger}$
}

\begin{abstract}
Introduction: A major consequence of ICU-acquired weakness (ICUAW) is diaphragm weakness, which prolongs the duration of mechanical ventilation. Hyperglycemia (HG) is a risk factor for ICUAW. However, the mechanisms underlying HG-induced respiratory muscle weakness are not known. Excessive reactive oxygen species (ROS) injure multiple tissues during $\mathrm{HG}$, but only one study suggests that excessive ROS generation may be linked to HG-induced diaphragm weakness. We hypothesized that HG-induced diaphragm dysfunction is mediated by excessive superoxide generation and that administration of a specific superoxide scavenger, polyethylene glycol superoxide dismutase (PEG-SOD), would ameliorate these effects.

Methods: $\mathrm{HG}$ was induced in rats using streptozotocin (60 $\mathrm{mg} / \mathrm{kg}$ intravenously) and the following groups assessed at two weeks: controls, HG, HG + PEG-SOD (2,000U/kg/d intraperitoneally for seven days), and HG + denatured (dn)PEG-SOD (2000U/kg/d intraperitoneally for seven days). PEG-SOD and dnPEG-SOD were administered on day 8 , we measured diaphragm specific force generation in muscle strips, force-pCa relationships in single permeabilized fibers, contractile protein content and indices of oxidative stress.

Results: HG reduced diaphragm specific force generation, altered single fiber force-pCa relationships, depleted troponin T, and increased oxidative stress. PEG-SOD prevented HG-induced reductions in diaphragm specific force generation (for example $80 \mathrm{~Hz}$ force was $26.4 \pm 0.9,15.4 \pm 0.9,24.0 \pm 1.5$ and $14.9 \pm 0.9 \mathrm{~N} / \mathrm{cm}^{2}$ for control, $\mathrm{HG}, \mathrm{HG}+$ PEG-SOD, and HG + dnPEG-SOD groups, respectively, $P<0.001$ ). PEG-SOD also restored HG-induced reductions in diaphragm single fiber force generation (for example, Fmax was 182.9 $\pm 1.8,85.7 \pm 2.0,148.6 \pm 2.4$ and $90.9 \pm 1.5 \mathrm{kPa}$ in control, HG, HG + PEG-SOD, and HG + dnPEG-SOD groups, respectively, $P<0.001)$. HG-induced troponin T depletion, protein nitrotyrosine formation, and carbonyl modifications were largely prevented by PEG-SOD.

Conclusions: HG-induced reductions in diaphragm force generation occur largely at the level of the contractile proteins, are associated with depletion of troponin T and increased indices of oxidative stress, findings not previously reported. Importantly, administration of PEG-SOD largely ablated these derangements, indicating that superoxide generation plays a major role in hyperglycemia-induced diaphragm dysfunction. This new mechanistic information could explain how HG alters diaphragm function during critical illness.
\end{abstract}

\section{Introduction}

A major consequence of ICU acquired skeletal muscle weakness (ICUAW) is respiratory muscle dysfunction which leads to prolonged duration of mechanical ventilation [1]. Importantly, a number of recent studies indicate that critically ill mechanically ventilated patients have severe respiratory muscle weakness, with diaphragm force

\footnotetext{
*Correspondence: lacall2@email.uky.edu

${ }^{+}$Equal contributors

Department of Internal Medicine, Division of Pulmonary, Critical Care and Sleep Medicine, University of Kentucky, 740 South Limestone Room L-543, Lexington, KY 40536-0284, USA
}

generation averaging only $23 \%$ of the level observed in healthy individuals [2-5]. In addition, clinical studies have identified a number of factors that are thought to contribute to ICU acquired diaphragm weakness including mechanical ventilation induced respiratory muscle inactivity, sepsis/infections, use of corticosteroids and hyperglycemia [6-8].

Several recent reports indicate that hyperglycemia detrimentally affects respiratory muscle performance in ICU patients [9-13]. Specifically, Van den Berghe et al. found that intensive insulin therapy (that is, administration of insulin to maintain blood glucose in the 80 to $110 \mathrm{mg} / \mathrm{dl}$

\section{Biomed Central}


range) in ICU patients markedly reduced the time required to wean patients from mechanical ventilation, shortened ICU stay, and was associated with decreased incidence of ICUAW $[9,13]$. In later work, this group showed that electromyographic abnormalities consistent with the diagnosis of ICUAW were prevented with intensive control of blood glucose levels $[10,12]$. In addition, more strict control of glucose reduced the duration of mechanical ventilation [10]. Moreover, numerous clinical studies in patients with a variety of diagnoses have now established that the presence of acute hyperglycemia is associated with poor outcomes, including increased mortality during critical illness [14,15].

The strongest evidence that hyperglycemia is a risk factor for acquired respiratory muscle weakness in ICU patients is borne out by these clinical observations [16]. However, the cellular mechanisms by which acute hyperglycemia induces respiratory muscle weakness are not known. On the other hand, previous studies indicate that hyperglycemia induces excessive generation of superoxide and other reactive oxygen species (ROS) in several tissues, including the vascular endothelium, the retina and kidneys [17-19] and that excessive ROS generation mediates the long term complications of diabetes in these organs. In addition, excessive ROS formation has been shown to mediate the development of skeletal muscle contractile dysfunction in several diseases, including sepsis, heart failure and inactivity induced muscle atrophy [20-26].

Only one previous animal study has provided a potential link between hyperglycemia induced diaphragm weakness and excessive ROS generation. In this study, Hida et al. [27] found that after two weeks of streptozotocin (STZ) induced hyperglycemia, diaphragm specific force generation was significantly reduced and that administration of a non-specific antioxidant, $\mathrm{N}$-acetyl cysteine (NAC) restored these reductions. In their conclusion, these authors speculated that NAC may have exerted its effects either by scavenging free radicals or by inhibiting tumor necrosis factor [27]. However, this study did not determine how hyperglycemia altered diaphragm contractility or assess if hyperglycemia actually induced oxidative stress in the diaphragm.

Given the recent recognition that hyperglycemia is a major clinical risk factor for ICU acquired diaphragm weakness, that excessive ROS generation plays a role in hyperglycemia-induced organ injury in multiple tissues (and, possibly, the diaphragm based on the single study cited above) and that excessive ROS generation has been implicated in diaphragm weakness in other conditions, we postulated that hyperglycemia may induce excessive superoxide generation in the diaphragm and may be responsible for the development of hyperglycemia-induced reductions in diaphragm contractility. Therefore, the purpose of the present study was to test this hypothesis using an animal model of hyperglycemia (that is, STZ-induced hyperglycemia) and to determine further the specific role of oxidative stress in modulating diaphragm dysfunction during hyperglycemia. We compared diaphragm force generation in intact diaphragm muscle strips, single fiber force-pCa relationships, levels of key contractile proteins and indices of ROS-mediated protein modifications in four groups of rats including sham treated euglycemic controls, hyperglycemic animals, hyperglycemic animals given a specific superoxide scavenger, polyethylene glycolsuperoxide dismutase (PEG-SOD) and hyperglycemic animals given enzymatically inactive, denatured PEG-SOD. Data were analyzed to determine the subcellular targets by which hyperglycemia reduces diaphragm force generating capacity and to determine if treatment with active PEG-SOD, a specific scavenger of excessive superoxide generation, would reverse hyperglycemia-induced alterations in the diaphragm.

We chose to focus on the diaphragm specifically because respiratory muscle weakness in the ICU is a major clinical problem [2,3], and diaphragm weakness in ICU patients has been shown to result in poor outcomes, including prolonged duration of mechanical ventilation, increased incidence of patient transfers to long term ventilator units and higher ICU mortality [2,3]. In addition, there is strong clinical data showing that strict glucose control reduces ICU acquired diaphragm weakness, shortening duration of mechanical ventilation and ICU length of stay in critically ill patients $[9,10,16]$. Finally, there is a paucity of mechanistic information regarding the effects of hyperglycemia on the diaphragm.

\section{Materials and Methods}

All studies were approved by the University of Kentucky Institutional Animal Care and Use Committee (Animal assurance number A3336-01). Care and handling of animals was in accordance with the guidelines of the National Institutes of Health Office of Lab Animal Welfare.

\section{Experimental models and protocols}

Experiments were performed using adult male Sprague Dawley rats weighing between 250 and $350 \mathrm{gm}$. Animals had unrestrained access to food and water throughout the study. To prevent dehydration, animals were housed individually and supplied with two water sources. Animals were monitored throughout experiments by members of the University of Kentucky Division of Laboratory Animal Resources as well as research personnel.

In pilot studies, we assessed diaphragm contractile function at several time points and noted consistent reductions in diaphragm contractility at two weeks. As a result, we chose to perform studies at this time point. This time point is relevant to ICU acquired diaphragm weakness which is most often clinically recognized when patients 
are unable to be weaned, which usually occurs after at least seven days of mechanical ventilation $[6,8]$.

Four groups of animals were studied, including: (1) sham treated euglycemic controls, (2) streptozotocin (STZ)-treated hyperglycemic animals, (3) STZ-treated hyperglycemic animals given a superoxide scavenger (PEG-SOD), and (4) STZ-treated hyperglycemic animals given enzymatically inactive, denatured PEG-SOD. Hyperglycemia was induced by a single tail vein injection of STZ (60 mg/kg) (Sigma Chemicals, St Louis, MO, USA) dissolved in citrate buffer ( $\mathrm{pH}$ 4.5). Sham-treated controls were injected via tail vein with an equivalent volume of citrate buffer alone. Tail vein blood was used to assess blood glucose levels on days 2 and 7 post injection of STZ or buffer in all animals to document hyperglycemia (glucose $>300 \mathrm{mg} / \mathrm{dl}$ ) in STZ-treated animals and euglycemia in controls. Measurements were performed using a commercially available glucometer (Precision Xtra, Abbott, Alameda, CA, USA). At one week after the initial injections of STZ or citrate buffer, animals were then treated with intraperitoneal injections of either saline, PEG-SOD (2,000 units/kg/day), or denatured PEG-SOD (heat denatured 2,000 units/ $/ \mathrm{kg} /$ day) for a total of seven days. On the day of sacrifice (two weeks after initial injections), a final blood glucose determination was made prior to administration of anesthetics, and animals were subsequently deeply anesthetized (pentobarbital $150 \mathrm{mg} /$ $\mathrm{kg}$ injected intraperitoneally) and diaphragms harvested. A portion of the left costal diaphragm was used immediately to assess force frequency relationships, a second section was removed for determination of single fiber force-pCa relationships, and a third section was frozen and stored $\left(\right.$ at $\left.-80^{\circ} \mathrm{C}\right)$ for biochemical assessments of contractile protein levels and ROS-mediated protein modifications.

\section{Measurement of diaphragm force-frequency relationships} Diaphragm specific force generation was assessed as previously reported [28-30]. Intact diaphragm strips were dissected from the left costal diaphragm and mounted vertically in water-jacketed organ baths (Radnoti, Monrovia, CA, USA) containing Krebs-Henseleit solution $\left(25^{\circ} \mathrm{C}\right.$, curare $50 \mathrm{mg} / \mathrm{L}, \mathrm{pH} 7.40, \mathrm{NaCl} 135 \mathrm{mM}, \mathrm{KCl} 5 \mathrm{mM}$, dextrose $11.1 \mathrm{mM}, \mathrm{CaCl}_{2} 2.5 \mathrm{mM}, \mathrm{MgSO}_{4} 1 \mathrm{mM}, \mathrm{NaHCO}_{3}$ $14.9 \mathrm{mM}, \mathrm{NaHPO}_{4} 1 \mathrm{mM}$, insulin 50 units/L, 95\% $\mathrm{O}_{2} / 5 \%$ $\mathrm{CO}_{2}$ ). The rib end of the strips was attached to the bottom of the baths by silk ties, and the tendon end was tied to a force transducer (Grass Technologies, West Warwick, RI, USA). Platinum field electrodes were placed around strips and connected to an amplifier (Biomedical Technology of America, Cleveland, Ohio, USA) attached to a Grass S48 stimulator (Grass Technologies). After a 15 minute equilibrium period, muscle length was adjusted to $L_{o}$ (the length at which force generation was maximum), stimulation current was adjusted to supramaximal levels and a force-frequency curve was constructed by stimulating strips at 1, 10, 20, 50, and $80 \mathrm{~Hz}$ (train duration $800 \mathrm{msec}$ ) with a 30 second rest period between adjacent stimulus trains. Force was recorded with a Gould 2600 strip chart recorder (Gould Instruments System, Cleveland, Ohio, USA). After force measurements were completed, transducers were calibrated with standard weights. Cross sectional area was calculated as muscle strip weight divided by muscle density (1.06) and muscle length; diaphragm specific force generation was then calculated as raw force divided by cross sectional area [31].

\section{Assessment of force-pCa relationships in single permeabilized diaphragm fibers}

Force-pCa curves from single permeabilized diaphragm fibers were determined as previously reported [24,32-34]. At the time of animal sacrifice, a portion of the diaphragm was carefully removed from its intercostal insertions and placed in a dissecting dish with a relaxing solution containing (in mM): $1.0 \mathrm{Mg}^{2+}, 5.0 \mathrm{MgATP}, 15$ phosphocreatine, 140.0 potassium methanesulfonate, 50.0 imidazole and 10.0 ethylene glycol tetraacetic acid (EGTA), with $\mathrm{pCa}>8.5, \mathrm{pH} 7.0$ and an ionic strength of 200. Protease inhibitors were added to the solution to protect the fibers from the damaging effects of proteolysis and included the following: $0.1 \mathrm{mM}$ phenylmethysulfonyl fluoride, $0.1 \mathrm{mM}$ leupeptin, $1.0 \mathrm{mM}$ benzamidine and $10 \mu \mathrm{M}$ aprotinin. The diaphragm was then divided into small strips and stored at $-20^{\circ} \mathrm{C}$ in the relaxing solution containing $50 \%$ glycerol and protease inhibitors for later experimentation. For the storage solution, CTP was used instead of ATP to prevent phosphorylation of the myosin light chains. All single-fiber assessments were completed within one week of animal sacrifice.

On the day that single fiber characteristics were assessed, diaphragm strips were removed from the storage solution, placed in the relaxing solution and equilibrated to room temperature. Bundles of approximately 10 fibers were gently separated from mid-costal diaphragm strips by pulling on one end of the muscle with a pair of fine-tipped forceps while the other end of the muscle was stationary. Following this, fiber bundles were permeabilized for 30 minutes in the relaxing solution containing $0.1 \%$ Triton X-100, an ionic detergent that eliminates the membranes of the sarcolemma, sarcoplasmic reticulum and mitochondria, leaving only the contractile proteins intact.

After incubation, bundles were removed from Triton $\mathrm{X}-100$, placed in the relaxing solution, and individual fibers teased from the muscle bundles. Single fibers were then mounted between an optoelectric force transducer (Scientific Instruments, Heidelberg, Germany) and a movable arm by wrapping the ends of each fiber around stainless steel clips. Fibers were adjusted to achieve a 
resting sarcomere length of $2.6 \mu \mathrm{m}$ as indicated by its helium-neon laser diffraction pattern. Length was constant throughout the protocol. The cross-sectional area of each fiber was determined after adjustment of the sarcomere length by measuring the diameter of the fiber using a micrometer attached to the eyepiece of the microscope and area was subsequently calculated assuming a cylindrical shape for the fiber.

Force versus $\mathrm{pCa}$ curves were then constructed for fibers by immersing them in solutions of increasing calcium concentrations and recording tension on a strip recorder. Once peak tension was achieved in a given $\mathrm{pCa}$ solution, fibers were rapidly switched to the next solution by means of a spring-loaded Plexiglas tray. The composition of all solutions for this study was calculated by using a computer program (Borland International, Scotts Valley, CA, USA) that takes into account stability constants and stock solutions to produce final solutions of the correct ionic strength and $\mathrm{pCa}$ (12). Specifically, the pCa solutions contained (in $\mathrm{mM}$ ): $1.0 \mathrm{Mg}^{2+}, 1.0$ MgATP, 15 phosphocreatine, 110.0 potassium methanesulfonate, 20.0 imidazole and 5.0 EGTA, with $\mathrm{pH}$ 7.0, and ionic strength of 200. Addition of different amounts of calcium yielded solutions of the desired $\mathrm{pCa}$. To establish the force versus $\mathrm{pCa}$ relationship, fibers were submerged in a solution containing no added calcium (pCa 8.5), followed by sequential exposure to 13 different calcium solutions, namely pCa $6.0,5.90,5.80,5.75,5.70$, $5.65,5.60,5.55,5.50,5.40,5.30,5.20$ and 5.0. These solutions correspond to a range of calcium concentrations of $10^{-6}$ to $10^{-5} \mathrm{M}$. Data were assessed using SigmaPlot software (version 12.0, Jandel Scientific) to determine the constant $N$ related to the steepness of the force versus $\mathrm{pCa}$ relationship ( $N$ is a measure of the extent of cooperativity among the thin filaments) and the calcium concentration required for half-maximal activation $\left(\mathrm{Ca}_{50}\right)(\mathrm{K})$ values for the force-pCa relationships from a best fit of the data to the modified Hill equation: \% maximum force $=100\left[\mathrm{Ca}^{2+}\right]^{\mathrm{N}} /$ $\left((\mathrm{K})^{\mathrm{N}}+\left[\mathrm{Ca}^{2+}\right]^{\mathrm{N}}\right)$. Averages and standard errors of the mean for $N$ values, $\mathrm{Ca}_{50}$, cross-sectional area, percentage of $\mathrm{F}_{\max }$ and absolute force (normalized for cross-sectional area) for individual diaphragm fibers were calculated for fibers from the experimental groups.

\section{Determination of diaphragm fiber type based on myosin heavy chain isoforms}

After determination of the force-pCa relationship, single fibers were stored in sample buffer at $-80^{\circ} \mathrm{C}$ and, subsequently, myosin heavy chain isoforms were determined for each individual fiber using gel electrophoresis according to previously established methods [35]. Fibers were classified based on their myosin heavy chain isoforms as either Type IIA, Type IIX, Type IIX/IIB, Type IIB or slow.

\section{Contractile protein level determination and assessment of ROS mediated protein modifications by western blots}

To determine if hyperglycemia induced alterations in the content of the contractile proteins, western blots of diaphragm homogenates were used to assess diaphragm levels of actin, actinin, tropomyosin and troponin T. In addition, since free radicals have been shown to modulate diaphragm dysfunction in a variety of animal models [23-25], we also examined diaphragm muscle homogenates for ROS-mediated protein modifications (nitrotyrosine side group formation, protein carbonyl formation). For these determinations, muscle samples were homogenized in buffer (10 mM beta-glycerophosphate, $50 \mathrm{mM}$ sodium fluoride, $1 \mathrm{mM}$ sodium, $20 \mathrm{mM}$ 4-(2-hydroxyethyl)-1piperazine-ethanesulfonic acid (HEPES), $2 \mathrm{mM}$ ethylenediaminetetraacetic acid (EDTA), $250 \mathrm{mM}$ sodium chloride, 2 microgram $/ \mathrm{ml}$ leupeptin, 2 microgram $/ \mathrm{ml}$ aprotinin, $1 \mathrm{mM}$ PMSF, 0.5 microgram $/ \mathrm{ml}$ benzamidine, and $1 \mathrm{mM}$ dithiothreitol (DTT)) in a $1 \mathrm{gm} / 10 \mathrm{ml}$ ratio, centrifuged at 3,000 g for 10 minutes. Protein contents of supernatants were assessed using the Bradford assay (BioRad Laboratories, Hercules, CA, USA). Supernatants were then diluted 1:1 with loading buffer $(126 \mathrm{mM}$ Tris$\mathrm{HCl}, 20 \%$ glycerol, 4\% SDS, 1.0\% 2-mercaptoethanol, 0.005\% bromophenol blue, $\mathrm{pH} 6.8$ ), boiled for five to seven minutes and equal amounts of protein ( 2 to 10 micrograms) were loaded onto Tris-glycine polyacrylamide gels. Proteins were separated by electrophoresis (Novex Minicell II, Carlsbad, CA, USA), transferred to polyvinylidene fluoride (PDVF) membranes and incubated over night at $4^{\circ} \mathrm{C}$ with primary antibodies to targeted proteins. The following reagents were used: anti-actin, anti-actinin, anti-tropomyosin and anti-troponin T (Sigma Aldrich, St. Louis, MO, USA), and anti-nitrotyrosine (EMD Millipore Corporation, Billerica, MA, USA). Protein carbonyl determinations were performed using the OxyBlot ${ }^{\mathrm{Tu}}$ Protein Oxidation Detection Kit (EMD Millipore Corporation) following the manufacturer's instructions. Following incubation in the primary antibody, membranes were washed and then subsequently incubated with horseradish peroxidase (HRP)-conjugated secondary antibodies and antibody binding detected using enhanced chemiluminescence (Western Lightning ${ }^{\circ}$-ECL, Perkin Elmer, Waltham, MA, USA). Densitometry was performed using a Microtek scanner (Carson, CA, USA) and UN-SCAN-IT software (Silk Scientific, Orem, UT, USA). To verify equal loading of lanes, blots were stripped and reprobed with antitubulin (Sigma Aldrich).

\section{Statistical analysis}

Analysis of variance (ANOVA) was employed to compare variables (for example, force) across groups of animals treated with different agents, with post-hoc testing (Tukey) to determine differences between groups. A $P<0.05$ was 
taken as indicating statistical significance. Data are presented as \pm 1 standard error of the mean (SEM).

\section{Results}

\section{Animal characteristics}

Control animals were euglycemic with glucose levels averaging $105+4 \mathrm{mg} / \mathrm{dl}$ (Table 1 ). At the time of sacrifice, glucose levels were greater than $350 \mathrm{mg} / \mathrm{dl}$ in all three STZ-treated groups. Importantly, administration of either active PEG-SOD or denatured PEG-SOD had no effect to lower glucose levels. Total body weight decreased significantly in all hyperglycemia groups; the reduction in body mass averaged $11 \pm 2 \%, 13 \pm 2 \%$ and $15 \pm 1 \%$ for hyperglycemia, hyperglycemia + PEG-SOD and hyperglycemia + denatured PEG-SOD groups, respectively $(P<0.001)$, when compared to control animals in which total body weight increased by $13 \pm 4 \%$. Total costal diaphragm weights also were significantly reduced in all hyperglycemia groups when compared to controls (Table 1). To further examine the effects of hyperglycemia and/or administration of PEG-SOD on diaphragm atrophy, we assessed the ratio of final diaphragm weights to final animal weights, reasoning that reductions in this ratio would be indicative of preferential diaphragm atrophy, rather than generalized reductions in muscle mass related to the global reduction in total body mass. As shown in the figure in Additional file 1: Figure S1, there was a trend for reductions in this ratio for the HG and HG + denatured PEG-SOD treated groups compared to the control group and HG + PEG-SOD groups, but these comparisons were not statistically significant $(P=0.24)$.

\section{Effects of hyperglycemia on diaphragm specific force generation}

The total force generated by a muscle is the product of muscle size (that is, total cross sectional area) and the force generating capacity per unit cross sectional area, otherwise known as muscle specific force. As shown in Figure 1, hyperglycemia resulted in a large reduction in diaphragm specific force, decreasing levels of force generated across the entire range of stimulation frequencies tested ( $P=.002$ for $1 \mathrm{~Hz}, P<0.001$ for all others). These data confirm the previous report by Hida et al. which showed that diaphragm specific force generation is reduced after two weeks of hyperglycemia [27].

\section{Effects of hyperglycemia on diaphragm single fiber force-pCa relationships}

To determine if the loss of diaphragm force generation in response to hyperglycemia was the consequence of alterations at the level of the contractile proteins, we assessed the force-pCa relationship in 360 single permeabilized diaphragm fibers (Figure 2). We found that hyperglycemia induced a large downshift in the diaphragm contractile protein force-pCa relationship, reducing Fmax from $182.9 \pm 1.85 \mathrm{kPa}$ to $85.7 \pm 1.99 \mathrm{kPa}$ (this is an index of actin-myosin crossbridge formation $)(P<0.001)$ and decreasing the coefficient of cooperativity, $\mathrm{N}$, from 5.98 to $5.17(P=0.015)$. Hyperglycemia did not, however, alter the calcium sensitivity $\left(\mathrm{pCa}_{50}\right)$ of the contractile proteins (Table 2).

Effect of PEG-SOD on diaphragm specific force generation in intact muscle strips

Administration of PEG-SOD largely reversed the effects of hyperglycemia on diaphragm specific force generation, restoring the force-frequency relationship measured on intact diaphragm strips (Figure 3). Specifically, diaphragm specific force generation (for example, $80 \mathrm{~Hz}$ force) was $26.4 \pm 0.9,15.4 \pm 0.9,24.0 \pm 1.5$ and $14.9 \pm 0.9 \mathrm{~N} / \mathrm{cm}^{2}$ for control, two week hyperglycemia, two week hyperglycemia + PEG-SOD and two week hyperglycemia + denatured PEG-SOD groups, respectively $(P<0.001)$. As shown in Figure 3, PEG-SOD restored force generation at all frequencies tested, similar to levels seen in control euglycemic animals.

\section{Effect of PEG-SOD on diaphragm single fiber force-pCa relationships}

We also assessed single diaphragm fiber force-pCa relationships in hyperglycemic animals given PEG-SOD and dnPEG-SOD. We found that PEG-SOD restored Fmax and $\mathrm{N}$ values to control levels and shifted force-pCa curves to levels similar to those for fibers from control, euglycemic animals (Figure 4$)(P<0.001$ for Fmax and $P<0.001$ for $\mathrm{N}$ values, respectively).

Table 1 Animal data

\begin{tabular}{lcccc}
\hline Experimental group & $\begin{array}{c}\text { Initial animal } \\
\text { weight (grams) }\end{array}$ & $\begin{array}{c}\text { Final animal } \\
\text { weight (grams) }\end{array}$ & $\begin{array}{c}\text { Costal diaphragm } \\
\text { weight (mg) }\end{array}$ & $\begin{array}{c}\text { Glucose } \\
\text { (mg/dL) }\end{array}$ \\
\hline Control & $306 \pm 13$ & $342 \pm 10$ & $725 \pm 61$ & $105 \pm 5$ \\
Hyperglycemia & $295 \pm 13$ & $261 \pm 9^{*}$ & $475 \pm 31^{*}$ & $434 \pm 18^{*}$ \\
Hyperglycemia + PEG-SOD & $325 \pm 13$ & $282 \pm 9^{*}$ & $566 \pm 26^{*}$ & $485 \pm 15^{*}$ \\
Hyperglycemia + denatured PEG-SOD & $297 \pm 9$ & $253 \pm 12^{*}$ & $453 \pm 38^{*}$ & $489 \pm 7^{*}$ \\
\hline
\end{tabular}

*Significantly different when compared to control group $(P<0.001)$. 
(A)

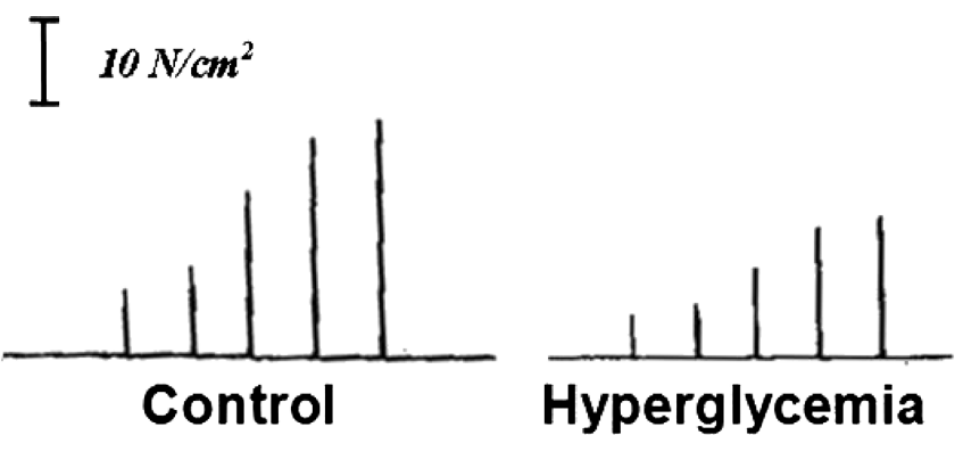

(B)

$\rightarrow$ Control

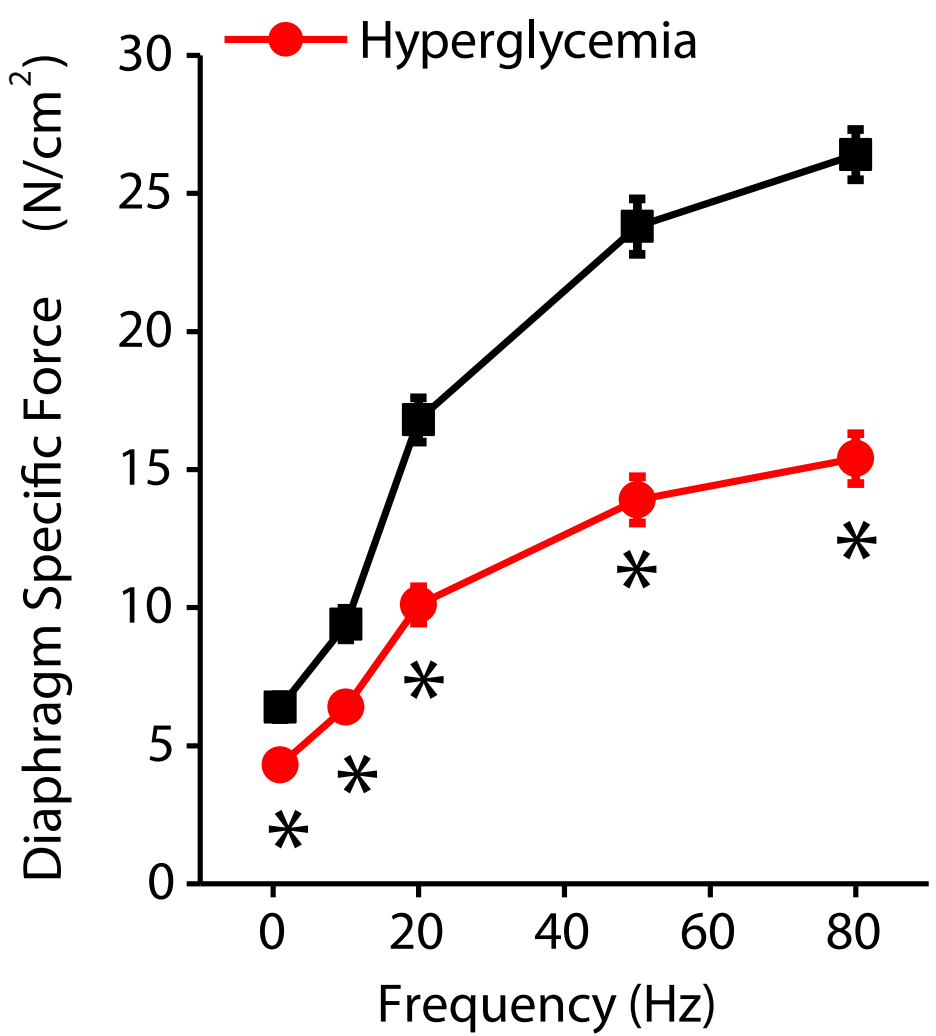

Figure 1 Hyperglycemia alters diaphragm force-frequency curves. A) demonstrates representative force frequency curves (raw data from 1 , 10, 20, 50 and $80 \mathrm{~Hz}$ stimulation frequencies) generated for intact diaphragm strips from a control animal treated with citrate buffer alone (left) and from a hyperglycemic animal two weeks after the initial injection of STZ (right). B) demonstrates mean data \pm SEM $(n=6)$ for control (black) and two week hyperglycemic animals (red). As shown, hyperglycemia induced large reductions in the diaphragm specific force generation (force/ cross sectional area) at all stimulation frequencies when compared to control animals. ( ${ }^{*} P=.002$ for $1 \mathrm{~Hz}, P \leq 0.001$ for all other stimulation frequencies). SEM, standard error of the mean; STZ, streptozotocin.

Previous studies which have examined force-pCa relationships in the rat diaphragm have reported fiber type specific changes in contractile protein characteristics $[35,36]$ as well as fiber type specific atrophy in a variety of animal models (chronic obstructive pulmonary disease (COPD), chronic corticosteroid treatment, cervical spinal cord injury induced inactivity and mechanical ventilation)
[37]. To determine if hyperglycemia induced alterations in single fiber force-pCa relationships were fiber-type specific, we analyzed single fiber maximal force generation, $\mathrm{pCa} 50, \mathrm{~N}$ values (obtained from the Hill equation), and fiber cross sectional area for Type IIA, IIX, IIX/IIB, IIB and slow fibers across the experimental groups (see the table in Additional file 2: Table S1 for details of this 


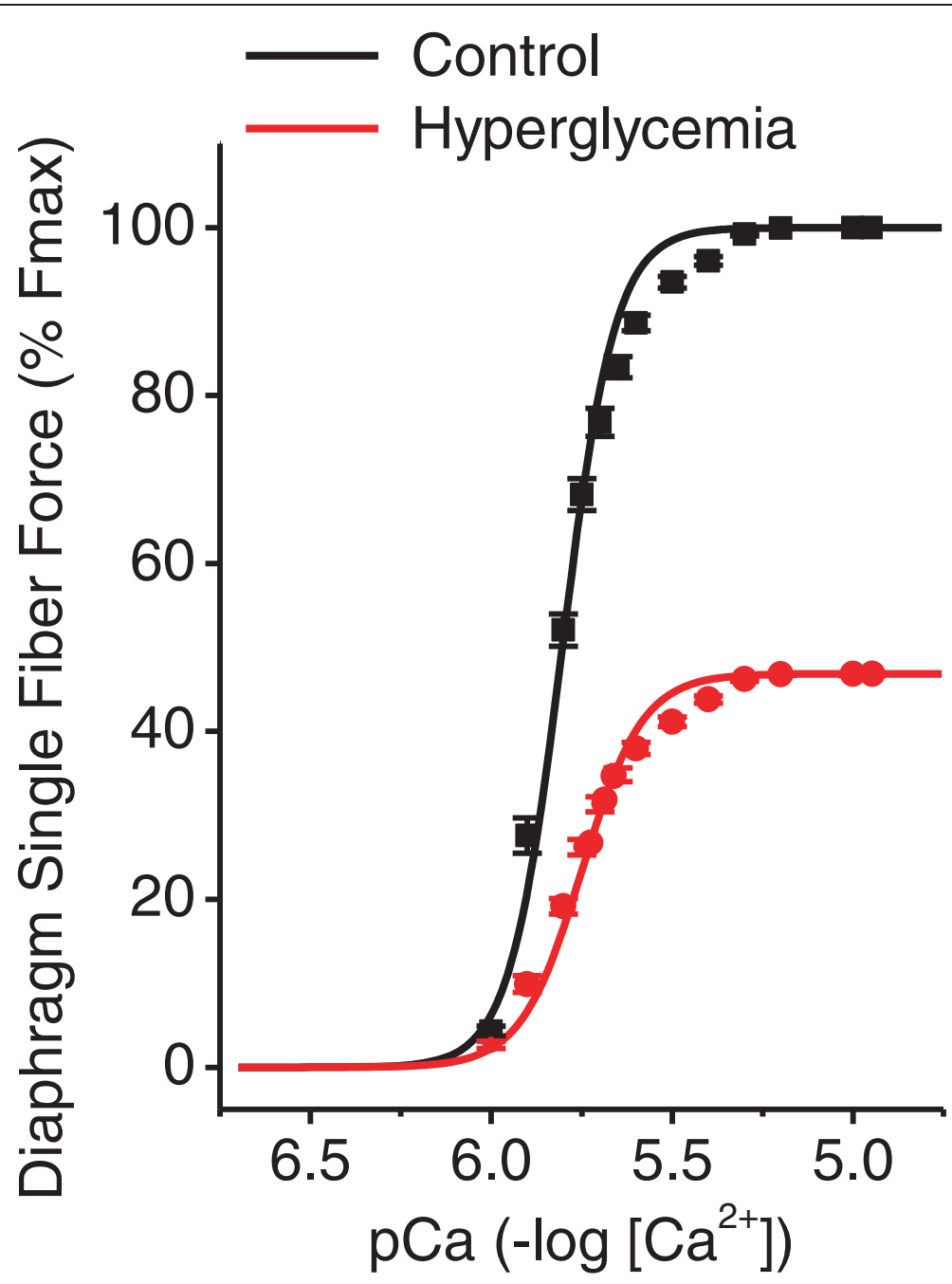

Figure 2 Hyperglycemia alters the force-pCa relationship in single permeabilized diaphragm fibers. Average force-Ca curves were constructed for single fibers from control (black) and two week hyperglycemic animals (red) using the Hill equation (15 fibers from each of six animals per condition for a total of 90 fibers per group). Symbols and error bars represent the mean \pm SEM of the data points obtained for each individual fiber. Force (Fmax) is the absolute force generation per cross sectional area of each individual fiber normalized to the percentage of the control fibers. pCa represents the $\left(-\log \left[\mathrm{Ca}^{2+}\right]\right)$ indicating that the calcium content in the solution increases along the X-axis. As shown, two weeks of hyperglycemia significantly alters the force-pCa relationship in single permeabilized diaphragm fibers, indicating that most of the hyperglycemia-induced diaphragm force reductions are due to alterations at the level of the contractile proteins $(P<0.001$ for force in fibers from hyperglycemic groups compared to control fibers at all pCa values greater than 6.0). SEM, standard error of the mean.

Table 2 Data from single permeabilized diaphragm fibers

\begin{tabular}{lccr}
\hline Experimental group & $\begin{array}{c}\text { Maximum force } \\
(\mathbf{k P a})\end{array}$ & $\begin{array}{c}\mathbf{N} \\
\text { value }\end{array}$ & $\mathbf{p C a _ { 5 0 }}$ \\
\hline Control & $182.9 \pm 1.8$ & $5.98 \pm 0.19$ & $5.81 \pm 0.01$ \\
Hyperglycemia & $85.7 \pm 2.0^{*}$ & $5.17 \pm 0.27^{*}$ & $5.69 \pm 0.07$ \\
Hyperglycemia + PEG-SOD & $148.6 \pm 2.4^{*}$ & $5.76 \pm 0.22$ & $5.78 \pm 0.01$ \\
Hyperglycemia + Denatured PEG-SOD & $90.9 \pm 1.5^{*}$ & $4.33 \pm 0.18^{*}$ & $5.72 \pm 0.01$ \\
\hline
\end{tabular}

Single fiber maximum force is reported as absolute force generation per fiber cross sectional area in $\mathrm{kPa} . \mathrm{N}$ is the Hill coefficient and indicates thin filament cooperativity. $\mathrm{pCa} 50$ is the calcium concentration at which half maximal activation occurs. Data are presented as the mean \pm standard error of the mean (SEM) and include all fiber types for each experimental group ( $n=90 /$ group). *Significantly different when compared to control group $(P<0.001)$. 


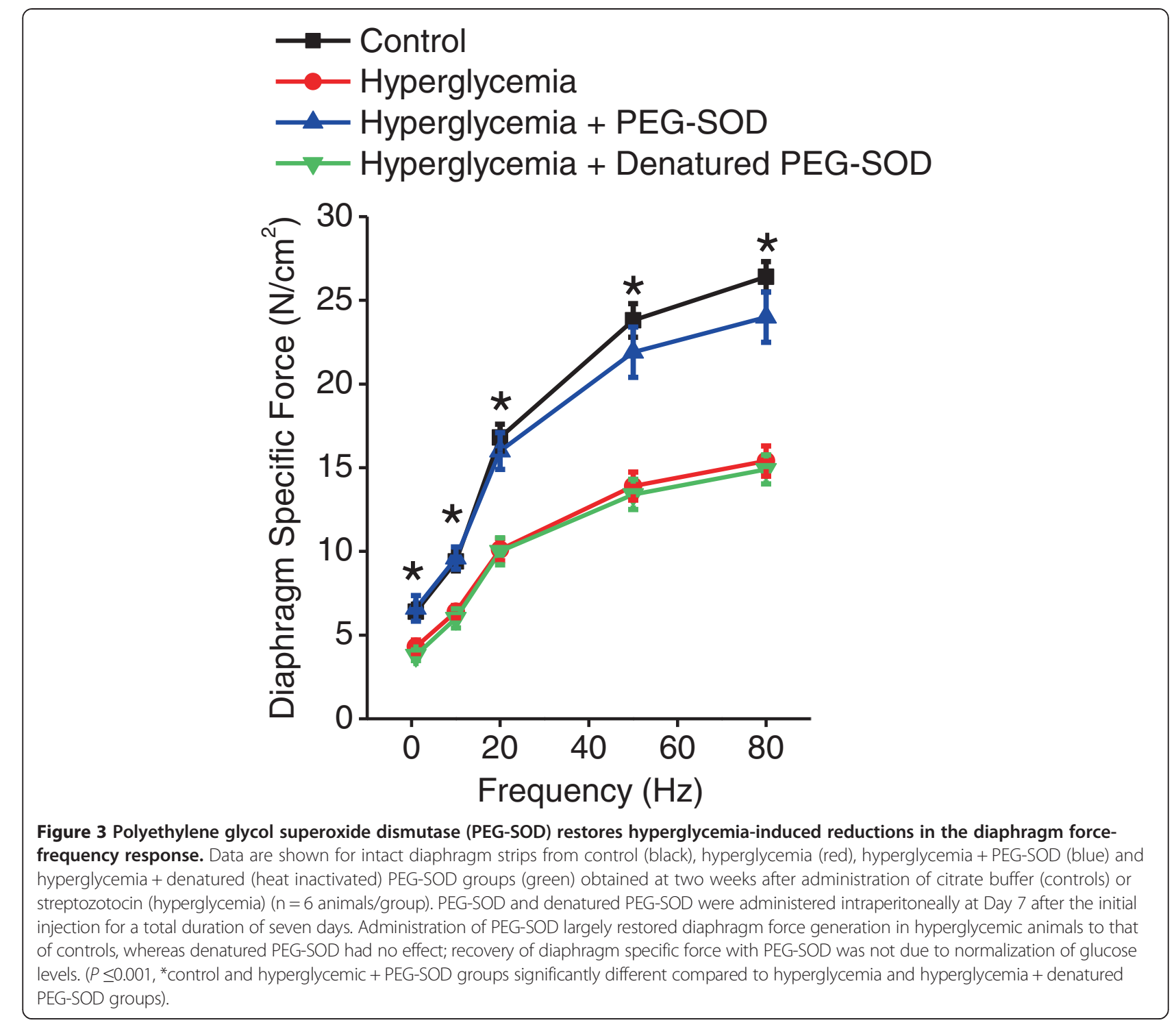

analysis). We found that the protective effect of PEG-SOD on force generation in single fibers was observed in all diaphragm fiber types (Figure 5). However, there were no fiber type specific differences in pCa50 values (calcium sensitivity) or $\mathrm{N}$ values (Hill coefficient) between control, HG, HG + PEG-SOD and HG + dnPEG-SOD groups. Hyperglycemia significantly decreased Type IIA fiber cross sectional area, which was not restored by administration of PEG-SOD.

Contractile protein levels and indices of protein oxidation There are several mechanisms by which pathological stresses can alter contractile protein function. One possible mechanism is via activation of proteolytic pathways with resultant cleavage and loss of specific contractile elements. A second process is via chemical modification of contractile elements through kinase-mediated phosphorylation reactions or sidegroup modifications by reactive species (for example, nitrosylation of tyrosine residues by peroxynitrite or carbonyl formation in response to reaction with ROS species). Moreover, a number of previous studies have shown that oxidative stress in the diaphragm is associated with alterations in diaphragm contractile performance [26,38,39].

To determine if hyperglycemia altered the level of contractile proteins, we measured levels of four proteins known to play key functions in contractile force generation, including actin, actinin, tropomyosin and troponin $\mathrm{T}$ (Figure 6). We found that hyperglycemia did not result in depletion of either actin, actinin or tropomyosin but significantly reduced levels of troponin $\mathrm{T}$, one of the key proteins involved in the regulation of crossbridge cycling. We also found that PEG-SOD attenuated this selective 


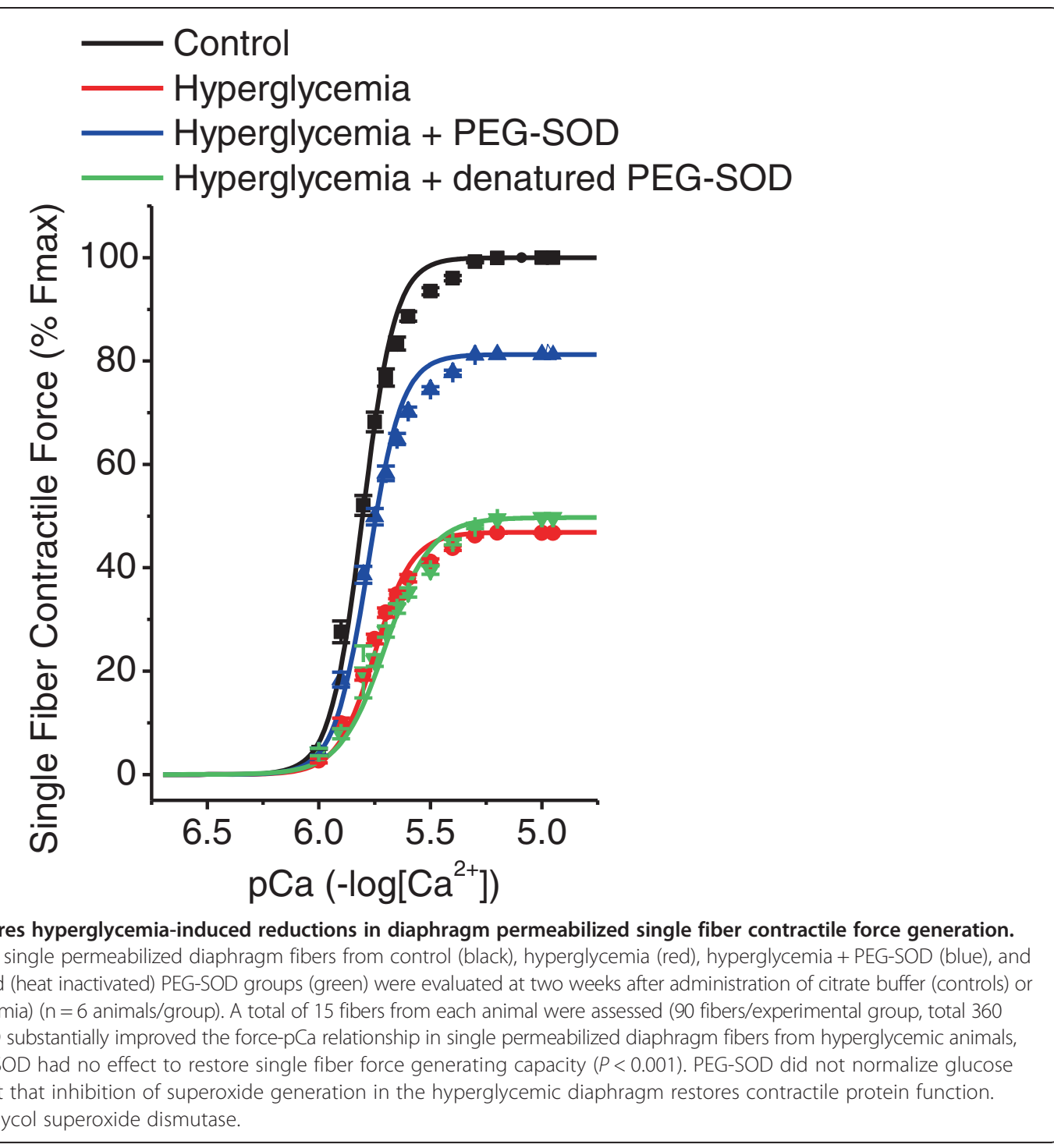

loss of troponin $\mathrm{T}$, restoring levels to near control values ( $P=0.001$ for comparison of all groups).

We also assessed if hyperglycemia induced protein modifications in the diaphragm known to be associated with oxidative stress (that is, nitrotyrosine and protein carbonyl formation). As shown in Figure 7, hyperglycemia induced large increases in diaphragm proteins with nitrosylated side groups, including a protein migrating with a molecular weight characteristic of myosin (Band 1). In addition, hyperglycemia significantly increased diaphragm protein carbonyl side group content (Figure 8) $(P<0.001)$, with large increases in the carbonyl content of nine protein bands. Administration of PEG-SOD largely ablated all hyperglycemia -induced increases in nitrotyrosine and protein carbonyl side group formation, suggesting that these increases are produced by ROS-mediated mechanisms. Administration of inactive, denatured PEG-SOD did not prevent hyperglycemia- induced increases in either diaphragm nitrotyrosine or protein carbonyl content.

\section{Discussion}

While a limited number of studies have examined the effects of hyperglycemia on the diaphragm, the majority of these reports have assessed changes in diaphragm force generation at much longer durations of hyperglycemia (four to eight weeks) compared to the current study, with some studies reporting increases in diaphragm specific force, while others report decreases [40,41]. However, neither of these studies investigated the role of ROS in the diaphragm alterations they observed. We are aware of only one previous study that assessed diaphragm specific force generation after two weeks of hyperglycemia, reporting reductions in diaphragm specific force generation similar to those that we observed and suggesting a possible link between ROS mediated processes and 
(A)

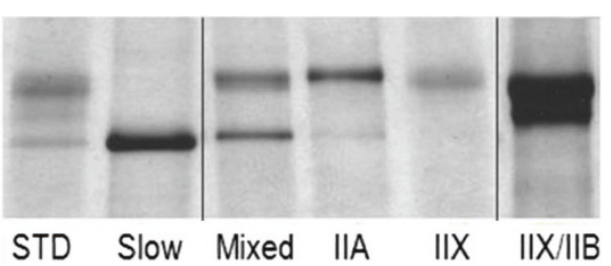

(B)

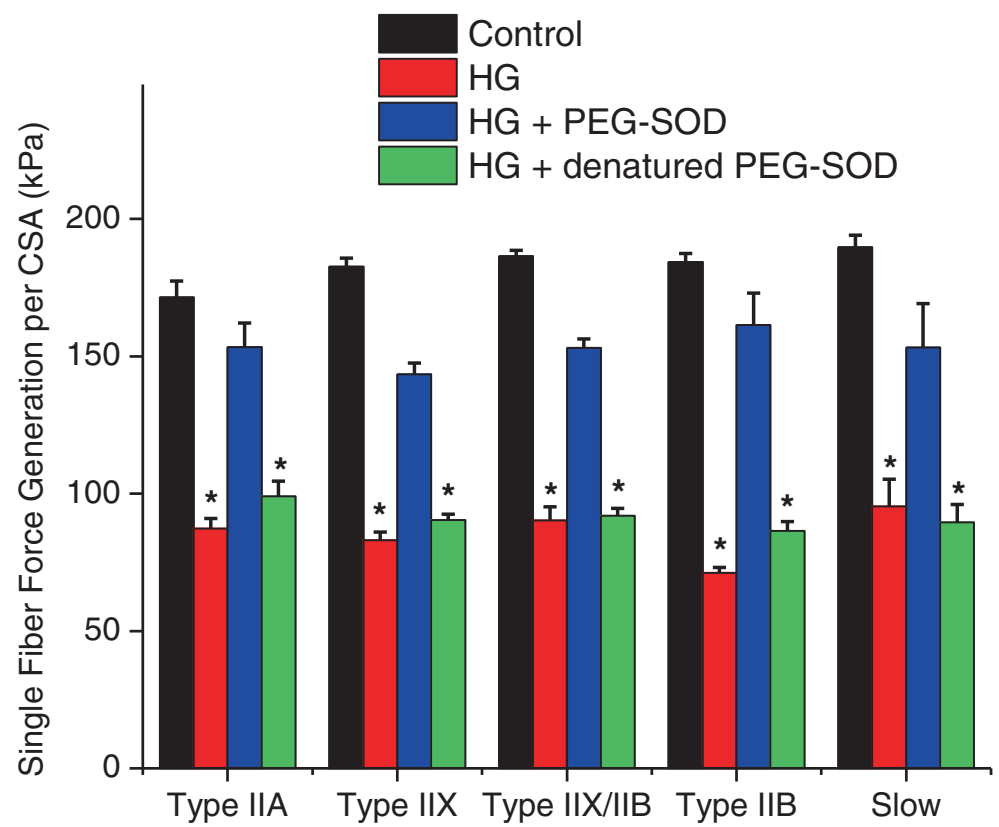

Figure 5 Hyperglycemia reduces single fiber contractile force generation in all fiber types. Fiber typing was performed for each diaphragm fiber in which force-pCa relationships were determined and then evaluated to assess if the changes in force were related to a specific fiber type. A total of 346 fibers were typed and subsequently classified as Type I (slow), Type IIA, Type II B, Type IIX, Type IIB/X and mixed based on the migration pattern of myosin heavy chains (determinations were not made for 14 fibers due to technical issues). A) depicts a representative gel for determination of individual fiber type. The first lane is a protein standard obtained from total diaphragm homogenates which contains all myosin heavy chain isoforms, the other lanes indicate myosin heavy chain isoforms from individual fibers. The image was obtained from the same gel, but lanes were not adjacent and are demarcated by the lines within the representative image. B) represents the effect of fiber type on maximal single fiber contractile force generation in response to hyperglycemia, hyperglycemia + PEG-SOD and hyperglycemia + denatured (heat inactivated) PEG-SOD. The absolute force generation/CSA in $\mathrm{kPa}$ is indicated for the different fiber types from the four experimental groups. As shown, hyperglycemia reduced single fiber contractile force generation in all diaphragm fiber types. Administration of PEG-SOD, but not denatured PEG-SOD, largely restored contractile force generation in single permeabilized diaphragm fibers independent of fiber type $\left(P<0.001,{ }^{*}\right.$ significantly different when compared to control and hyperglycemia + PEG-SOD fibers). PEG-SOD, polyethylene glycol superoxide dismutase.

reductions in diaphragm contractility [27]. However, this study did not examine intracellular targets of hyperglycemia-induced changes in the diaphragm, did not examine single diaphragm fiber force generation, did not assess contractile protein content and did not measure any indices of diaphragm oxidative stress in response to hyperglycemia.

In contrast to this previous work, we found that hyperglycemia induced reductions in diaphragm contractility occur largely at the level of the contractile proteins with resultant loss of diaphragm troponin $\mathrm{T}$ and increased indices of oxidative stress. Moreover, the present work is the first to show that administration of a selective superoxide scavenger, PEG-SOD, completely reversed hyperglycemia- induced diaphragm weakness, increasing force generation in response to the entire range of physiologically relevant stimulation frequencies. In addition, by using single permeabilized fiber techniques, we demonstrate that the contractile proteins are a major intracellular target of hyperglycemia with hyperglycemia inducing both a reduction in maximum contractile protein force generation and a reduction in thin filament interactions. We also show that administration of PEG-SOD reverses hyperglycemia -induced alterations in contractile protein function, improving maximum force generating capacity and restoring thin filament cooperativity, providing evidence that this process is, in part, mediated by free radical generation and, specifically, by excessive superoxide generation. 

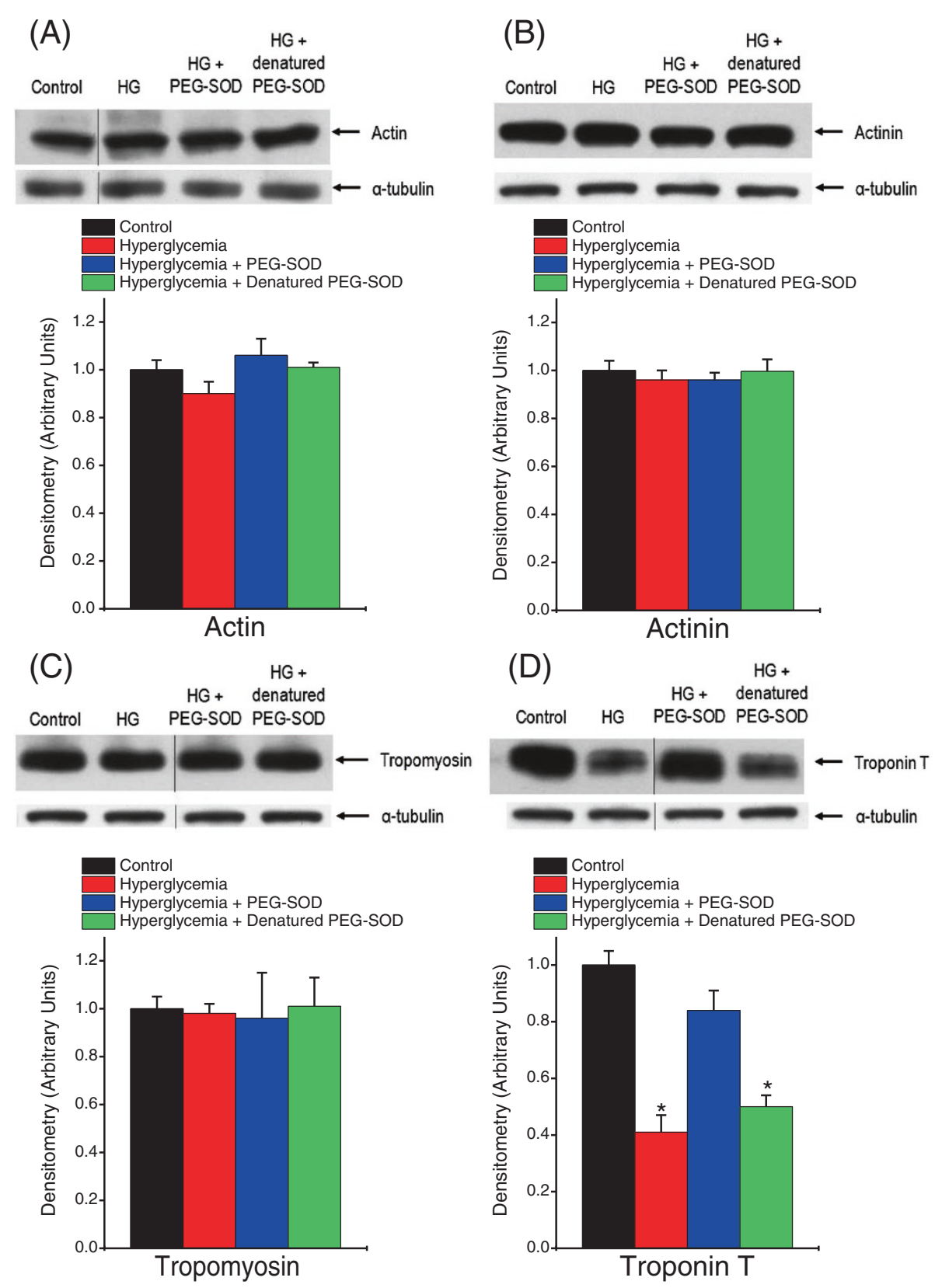

Figure 6 Hyperglycemia induces selective depletion of diaphragm troponin T. Representative western blots and mean densitometry of key contractile proteins from diaphragm homogenates from control (black), hyperglycemic (red), hyperglycemic + PEG-SOD (blue), and hyperglycemic + denatured (heat inactivated) PEG-SOD groups ( $\mathrm{n}=6$ for each comparison). Images were obtained from the same gel, but lanes were not adjacent and are demarcated by the lines within the representative image. Actin levels are shown in A), actinin levels in B), tropomyosin levels in C) and troponin T levels in D). Blots were reprobed with tubulin as a loading control. Densitometry is presented in arbitrary units and was normalized to control values. There were no significant differences in the protein contents of actin, actinin, or tropomyosin between groups. On the other hand, troponin $T$ levels were significantly decreased with hyperglycemia; this loss of troponin T was prevented with administration of PEG-SOD, but not with denatured PEG-SOD $(P<0.001)$. These data demonstrate that a superoxide scavenger preserves hyperglycemia -induced loss of troponin $T$ in the diaphragm. (* significantly different from control and hyperglycemic + PEG-SOD groups). PEG-SOD, polyethylene glycol superoxide dismutase.

It is known that hyperglycemia increases free radical generation in tissues other than skeletal muscle $[17,18,42]$. More importantly, this previous work also indicates that excessive generation of superoxide and other ROS (for example, peroxynitrite, hydrogen peroxide) plays an important role in the genesis of hyperglycemia-induced tissue damage in several organs $[17,18,43,44]$. For example, hyperglycemia-induced endothelial dysfunction is thought to be linked to excessive glucose entry into endothelial cells leading to an increase in NADH production within the 


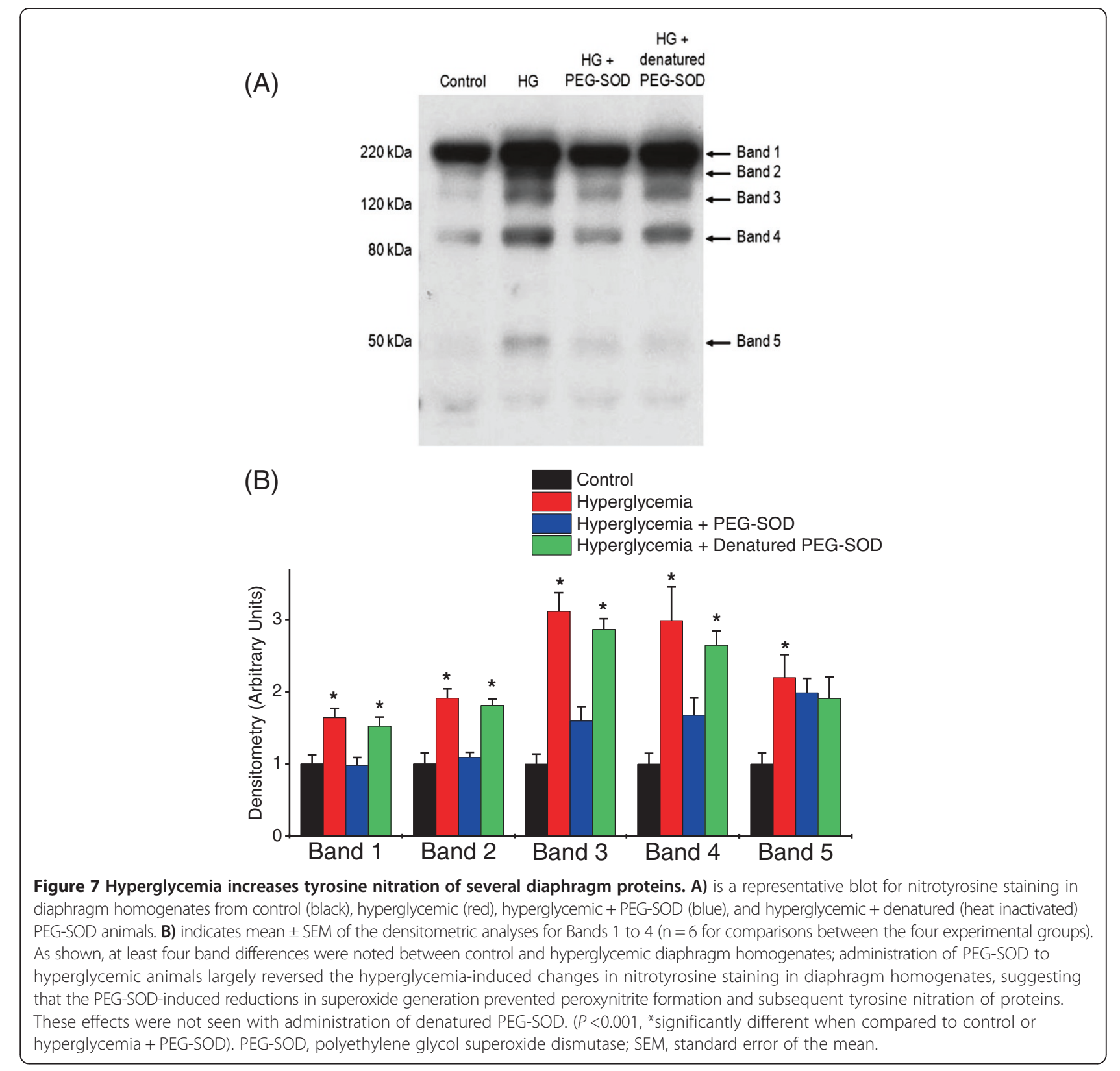

mitochondria, enhanced reduction of the proximal portion of the electron transport chain and resultant increases in electron transport chain superoxide generation $[45,46]$. Inhibition of this mechanism of superoxide generation has been shown to prevent hyperglycemia-induced endothelial dysfunction in animal models [32]. Similarly, hyperglycemia-induced retinal damage has been linked to retinal superoxide generation by NADPH oxidase, with reports indicating that administration of superoxide scavengers prevents diabetes-induced retinal damage $[17,18]$. The present study extends this previous work, indicating that a superoxide scavenger can also prevent hyperglycemia-induced diaphragm weakness. We did not identify the source of excessive diaphragm ROS generation in response to hyperglycemia in the present study, but these previous studies as well as studies examining ROS production in skeletal muscle, suggest a number of potential sites including the mitochondrial electron transport chain, NADPH oxidase, xanthine oxidase and uncoupled nitric oxide synthase $[47,48]$. While mitochondria are implicated as the most important source of superoxide in skeletal muscle, a recent study suggests that NADPH oxidase is the major source of superoxide generation in skeletal muscle at rest and during contraction [49]. Ongoing studies in our lab are designed to elucidate which of these sources of superoxide generation 


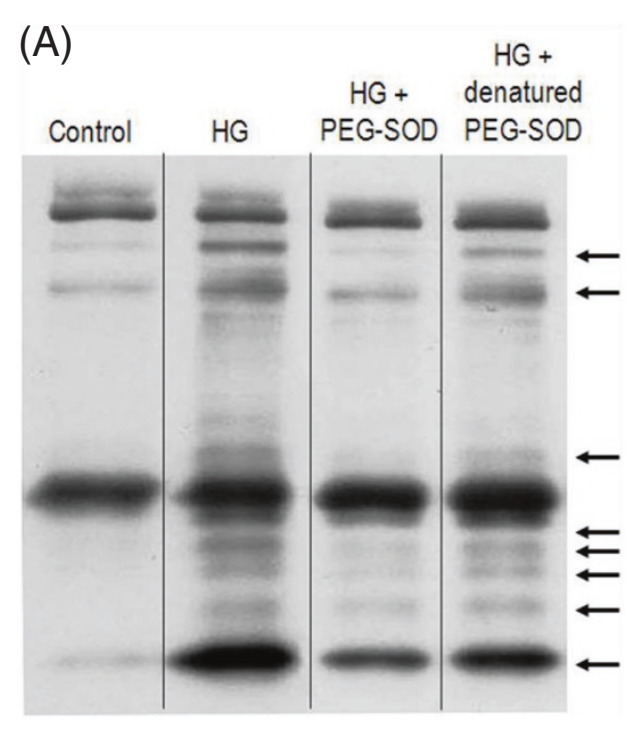

(B)
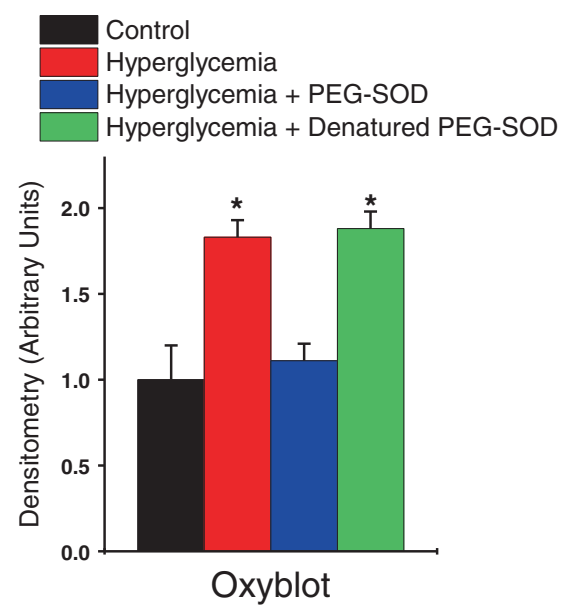

Figure 8 Hyperglycemia increases protein carbonyl modifications in the diaphragm. A) is a representative oxyblot in diaphragm homogenates from the four experimental groups. Image was obtained from the same gel, but lanes were not adjacent and are demarcated by the lines within the representative image. As shown, hyperglycemia produced multiple protein carbonyl modifications of diaphragm proteins. B) is the mean \pm SEM of the total lane densitometry of the four experimental groups $(n=4)$. Administration of PEG-SOD, but not denatured PED-SOD, largely abolished these modifications indicating that excessive superoxide generation mediates this process. $\left(P<0.001\right.$, ${ }^{*}$ significantly different when compared to control or hyperglycemia + PEG-SOD). PEG-SOD, polyethylene glycol superoxide dismutase; SEM, standard error of the mean.

are pathogenetically linked to the development of hyperglycemia-induced diaphragm dysfunction.

Our observation that ROS play a role in producing diaphragm weakness during hyperglycemia is consistent with several previous reports indicating that excessive ROS generation mediates the development of diaphragm dysfunction in a variety of animal models of disease including congestive heart failure, mechanical ventilationinduced inactivity, sepsis, and during fatigue [23,25,50,51]. In these other conditions, as in the present study, there is evidence of excessive ROS generation in the diaphragm, protection from force loss when superoxide scavengers are administered, and superoxide dependent reductions in parameters of single fiber contractile protein function (for example, reductions in the Fmax) [24]. Additional data suggest that there are several mechanisms by which free radical species alter contractile protein function. First, we have shown that when various free radical generating solutions are applied directly to the diaphragm single fiber contractile proteins, superoxide anions, hydroxyl radicals and peroxynitrite each depress maximal contractile protein force generation (Fmax) [32,34]. In addition to these direct effects on contractile proteins, ROS have been shown to activate a variety of signaling kinases in skeletal muscle including JNK, PKR and p38 [52-54]. These kinases, in turn, trigger alterations in a variety of downstream pathways in skeletal muscle, including the intrinsic caspase pathway, the extrinsic caspase pathway, components of the proteasomal degradation pathway and factors regulating protein translation (for example, eIF2 $\alpha$, SK6)
[29,30,55-62]. In addition, ROS are also known to activate the calpain proteolytic system in skeletal muscle $[58,61]$. While the exact effects of activated calpain, the activated proteasomal system and a sudden reduction in protein translation on contractile protein function are not known, activated caspase induces alterations in contractile protein function that are similar to those observed in response to hyperglycemia in the present study, that is, caspase induces large reductions in Fmax and alters $\mathrm{N}$, the index of thin filament cooperativity [63]. In addition, Smuder et al. reported that oxidative modification of diaphragm myofibrillar proteins increases their susceptibility to caspase and calpain mediated degradation [57]. As a result, the pattern of alterations in contractile protein function induced by hyperglycemia in the present study is similar to that seen in response to several known effects of ROS, that is, the direct effects of ROS on contractile protein function and the effects of ROS triggered proteolysis on the contractile proteins. We also found that hyperglycemia induced a significant reduction in troponin $\mathrm{T}$ levels, with this effect inhibited by PEG-SOD administration. Troponin $\mathrm{T}$ is a target of both activated caspase and activated calpain $[64,65]$, and it is possible that hyperglycemia induced loss of this particular contractile protein through ROS mediated activation of these proteolytic enzymes. Additional work will be needed to determine the exact role of the various downstream effects of ROS in altering contractile protein function in hyperglycemia and to also evaluate the specific mechanisms responsible for the observed depletion of troponin. 


\section{Limitations}

There are several elements of our methodology that require careful consideration. We chose to use the STZ model to induce hyperglycemia in our animals. While this is a well established model of hyperglycemia which reproducibly produces similar, sustained elevations in blood glucose levels in animals, a potential criticism is that STZ per se could have some unrecognized toxicity that may directly affect muscle function, potentially influencing our results. To exclude this possibility, we administered insulin to STZ animals $(\mathrm{n}=3)$ and compared the forcefrequency relationship in insulin-treated STZ animals to those animals given STZ alone, reasoning that if STZ per se was responsible for the alterations in diaphragm function we observed, these abnormalities would not improve with restoration of euglycemia. We found that insulin treatment markedly improved diaphragm contractility in STZ-treated animals (see figure in Additional file 3: Figure S2), indicating that in our model, diaphragm weakness is not due to a toxic effect of STZ, but rather, is secondary to the effects of hyperglycemia.

Another potential criticism is that the STZ model does not completely replicate the hyperglycemia of stress seen in critically ill patients. Studies have suggested that hyperglycemia in ICU patients primarily arises from increased insulin resistance rather than loss of insulin secretion [66]. In the present study, we employed a dose of STZ that was sufficiently low such that complete loss of insulin secretion would not occur $[67,68]$. Moreover, at these doses of STZ, animals gradually develop peripheral insulin resistance over a period of weeks [69]. As a result, this model induces a form of hyperglycemia (peripheral resistance to insulin, moderate reductions in insulin levels) that is a reasonable simulation of what occurs in critically ill patients. Recently, other investigators have used animal models of critical illness (trauma, hemorrhage, sepsis, burn injury) in combination with glucose loading to mimic stress induced hyperglycemia [70-72]. However, use of such complex models would make it difficult to discriminate between the effects of the underlying injury from the effects of hyperglycemia on diaphragm function. Nevertheless, it will be of interest to determine if the same phenomena observed in the present study are also observed in some of these other animal models.

Our data provide strong evidence that hyperglycemiainduced superoxide generation mediates diaphragm weakness. However, in the present study, we did not identify the intracellular source of superoxide. As indicated above, we are performing additional studies to identify the precise source of superoxide generation in the diaphragm in response to hyperglycemia. In addition, the fact that we observed increased nitrotyrosine formation in diaphragm homogenates suggests that hyperglycemia may also result in excessive generation of nitric oxide and/or reactive nitrogen species, and the role of nitric oxide in the genesis of hyperglycemia-induced diaphragm weakness warrants further exploration. Finally, while we provide evidence of ROS mediated protein modifications in the diaphragm, in addition to depletion of troponin $\mathrm{T}$, future studies will be needed to identify further other protein modifications as well as the proteolytic processes that may account for hyperglycemia-induced physiologic derangements in diaphragm contractility. Nonetheless, our findings represent an important first step in characterizing the effects of hyperglycemia on respiratory muscle function.

\section{Conclusions}

Previous work indicates that poor glycemic control in critically ill patients increases the incidence of ICU acquired diaphragm weakness and prolongs duration of mechanical ventilation. The present study provides mechanistic information regarding the effects of hyperglycemia on diaphragm contractility, and potentially explains how this specific risk factor might contribute to diaphragm weakness and impact weaning from mechanical ventilation in critically ill patients. The obvious treatment for hyperglycemia in critical illness is insulin therapy; however, the data that indicate that this approach prevents ICU acquired diaphragm weakness show that strict glycemic control with intensive insulin therapy is required. Moreover, recent studies suggest that this approach increases ICU mortality, primarily due to complications arising from hypoglycemia [73-75], and as such, current clinical recommendations for the management of hyperglycemia in critically ill patients do not support the use of strict glucose control. Importantly, the data from the present study show that hyperglycemia-induced respiratory muscle weakness can be prevented by administration of a superoxide scavenger (PEG-SOD), as this agent dramatically restored diaphragm function in hyperglycemic animals despite having no effect on glucose levels. Moreover, diaphragm weakness improved dramatically even though treatment with PEG-SOD was delayed for one week after hyperglycemia was present. Therefore, it seems reasonable to speculate that treatment with agents that target ROS may provide an alternative approach to prevent hyperglycemia-induced respiratory muscle dysfunction in critical illness. Nonetheless, additional clinical studies will be needed to assess the efficacy of such therapies in mechanically ventilated hyperglycemic ICU patients.

\section{Key messages}

- Hyperglycemia induces diaphragm weakness and is associated with loss of troponin $\mathrm{T}$ and increased markers of oxidative stress.

- Alterations in diaphragm specific force generation in response to hyperglycemia occur at the level of the 
contractile proteins and are independent of diaphragm fiber type.

- Administration of PEG-SOD, a specific scavenger of superoxide, prevents hyperglycemia-induced diaphragm weakness, restoring both intact diaphragm force generation as well as single fiber diaphragm force generation without lowering glucose levels.

- Our data identify new mechanisms for hyperglycemia induced diaphragm weakness, and potentially explain how poor glucose control might potentiate the development of diaphragm weakness and prolong the duration of mechanical ventilation during critical illness.

\section{Additional files}

Additional file 1: Figure S1. Final diaphragm weight to final animal weight ratios. This is a graph demonstrating the final diaphragm weight to final animal weight ratios in the experimental groups.

Additional file 2: Table S1. Fiber type specific data in single permeabilized diaphragm fibers from all experimental groups. This is a table showing the detailed analyses of single fiber experiments based on fiber type as determined by the myosin heavy chain content in individual fibers; included are fiber type specific parameters of maximal force generation per cross sectional area $(\mathrm{kPa})$, cross sectional area, $\mathrm{N}$ values (Hill coefficient) and the $\mathrm{pCa}_{50}$

Additional file 3: Figure S2. Effect of insulin treatment on diaphragm specific force generation. This figure demonstrates the effects of insulin treatment in hyperglycemic animals on the diaphragm specific force generation.

\section{Abbreviations}

ANOVA: analysis of variance; $\mathrm{Ca}_{50}$ : calcium concentration required for half-maximal activation; COPD: chronic obstructive pulmonary disease; CSA: cross sectional area; dnPEG-SOD: denatured polyethylene glycol conjugated superoxide dismutase; DTT: dithiothreitol; EGTA: ethylene glycol tetraacetic acid; HEPES: 4-(2-hydroxyethyl)-1-piperazine-ethanesulfonic acid; HG: hyperglycemia; HRP: horseradish peroxidase; ICUAW: intensive care unit acquired weakness; JNK: c-Jun N-terminal kinase; kPa: kilopascal; NAC: N-acetyl cysteine; $\mathrm{NADH}$ : reduced form of nicotinamide adenine dinucleotide; NADPH oxidase: nicotinamide adenine dinucleotide phosphate-oxidase; pCa: -[log] calcium concentration; PDVF: polyvinylidene fluoride; PEG-SOD: polyethylene glycol conjugated superoxide dismutase; PKR: double-stranded RNA-dependent protein kinase; PMSF: phenylmethanesulfonylfluoride; ROS: reactive oxygen species; SDS: sodium dodecyl sulfate; SEM: standard error of the mean; STZ: streptozotocin.

\section{Competing interests}

Both authors declare that they have no competing interests.

\section{Authors' contributions}

LAC and GSS conceived and designed the study, supervised the research process, analyzed and interpreted the data, drafted the manuscript and approved the final manuscript. Both authors read and approved the final manuscript.

\section{Acknowledgements}

This work was supported by funds provided by the National Institutes of Health from grants awarded to LAC (R01HL112085, R01HL080609) and to GSS (R01HL113494, R01HL080429, R01HL081525). In addition, the authors would like to thank Drs. Wenyi Wang and Shanshan Zhan for their technical assistance in carrying out some of the studies.

Received: 12 December 2013 Accepted: 24 April 2014

Published: 3 May 2014

\section{References}

1. Latronico N, Bolton CF: Critical illness polyneuropathy and myopathy: a major cause of muscle weakness and paralysis. Lancet Neurol 2011, 10:931-941.

2. Supinski GS, Callahan LA: Diaphragm weakness in mechanically ventilated critically ill patients. Crit Care 2013, 17:R120

3. Demoule A, Jung B, Prodanovic H, Molinari N, Chanques G, Coirault C, Matecki S, Duguet A, Similowski T, Jaber S: Diaphragm dysfunction on admission to ICU: prevalence, risk factors and prognostic impact - a prospective study. Am J Respir Crit Care Med 2013, 188:213-219.

4. Hermans G, Agten A, Testelmans D, Decramer M, Gayan-Ramirez G: Increased duration of mechanical ventilation is associated with decreased diaphragmatic force: a prospective observational study. Crit Care 2010, 14:R127.

5. Watson AC, Hughes PD, Louise Harris M, Hart N, Ware RJ, Wendon J, Green M, Moxham J: Measurement of twitch transdiaphragmatic, esophageal, and endotracheal tube pressure with bilateral anterolateral magnetic phrenic nerve stimulation in patients in the intensive care unit. Crit Care Med 2001, 29:1325-1331.

6. De Jonghe B, Bastuji-Garin S, Sharshar T, Outin H, Brochard L: Does ICU-acquired paresis lengthen weaning from mechanical ventilation? Intensive Care Med 2004, 30:1117-1121.

7. Hermans G, De Jonghe B, Bruyninckx F, Berghe GV: Clinical review: critical illness polyneuropathy and myopathy. Crit Care 2008, 12:238.

8. De Jonghe B, Lacherade JC, Durand MC, Sharshar T: Critical illness neuromuscular syndromes. Neurol Clin 2008, 26:507-520. ix.

9. van den Berghe $G$, Wouters $P$, Weekers F, Verwaest $C$, Bruyninckx F, Schetz M, Vlasselaers D, Ferdinande P, Lauwers P, Bouillon R: Intensive insulin therapy in critically ill patients. N Engl J Med 2001, 345:1359-1367.

10. Hermans G, Wilmer A, Meersseman W, Milants I, Wouters PJ, Bobbaers H, Bruyninckx F, Van den Berghe G: Impact of intensive insulin therapy on neuromuscular complications and ventilator dependency in the medical intensive care unit. Am J Respir Crit Care Med 2007, 175:480-489.

11. Hermans G, De Jonghe B, Bruyninckx F, Van den Berghe G: Interventions for preventing critical illness polyneuropathy and critical illness myopathy. Cochrane Database Syst Rev 2009, 1:CD006832.

12. Hermans G, Schrooten M, Van Damme P, Berends N, Bouckaert B, De Vooght W, Robberecht W, Van den Berghe G: Benefits of intensive insulin therapy on neuromuscular complications in routine daily critical care practice: a retrospective study. Crit Care 2009, 13:R5

13. Van den Berghe G, Wilmer A, Hermans G, Meersseman W, Wouters PJ, Milants I, Van Wijngaerden E, Bobbaers H, Bouillon R: Intensive insulin therapy in the medical ICU. N Engl J Med 2006, 354:449-461.

14. Lipton JA, Barendse RJ, Van Domburg RT, Schinkel AF, Boersma H, Simoons MI, Akkerhuis KM: Hyperglycemia at admission and during hospital stay are independent risk factors for mortality in high risk cardiac patients admitted to an intensive cardiac care unit. Eur Heart J Acute Cardiovasc Care 2013, 2:306-313.

15. Shimoyama T, Kimura K, Uemura J, Saji N, Shibazaki K: Elevated glucose level adversely affects infarct volume growth and neurological deterioration in non-diabetic stroke patients, but not diabetic stroke patients. Eur J Neurol 2014, 21:402-410.

16. Hermans G, De Jonghe B, Bruyninckx F, Van den Berghe G: Interventions for preventing critical illness polyneuropathy and critical illness myopathy. Cochrane Database Syst Rev 2014, 1:CD006832.

17. Sedeek M, Montezano AC, Hebert RL, Gray SP, Di Marco E, Jha JC, Cooper ME, Jandeleit-Dahm K, Schiffrin EL, Wilkinson-Berka JL, Touyz RM: Oxidative stress, Nox isoforms and complications of diabetes-potential targets for novel therapies. J Cardiovasc Transl Res 2012, 5:509-518.

18. Giacco F, Brownlee M: Oxidative stress and diabetic complications. Circ Res 2010, 107:1058-1070.

19. Munusamy S, MacMillan-Crow LA: Mitochondrial superoxide plays a crucial role in the development of mitochondrial dysfunction during high glucose exposure in rat renal proximal tubular cells. Free Radic Biol Med 2009, 46:1149-1157.

20. Callahan LA, Supinski GS: Sepsis-induced myopathy. Crit Care Med 2009, 37:S354-\$367.

21. Callahan LA, Stofan DA, Szweda LI, Nethery DE, Supinski GS: Free radicals alter maximal diaphragmatic mitochondrial oxygen consumption in endotoxin-induced sepsis. Free Radic Biol Med 2001, 30:129-138.

22. Nethery D, DiMarco A, Stofan D, Supinski G: Sepsis increases contraction-related generation of reactive oxygen species in the diaphragm. J Appl Physiol 1999, 87:1279-1286 
23. Powers SK, Hudson MB, Nelson WB, Talbert EE, Min K, Szeto HH, Kavazis AN, Smuder AJ: Mitochondria-targeted antioxidants protect against mechanical ventilation-induced diaphragm weakness. Crit Care Med 2011, 39:1749-1759.

24. Callahan LA, Nethery D, Stofan D, DiMarco A, Supinski G: Free radical-induced contractile protein dysfunction in endotoxin-induced sepsis. Am J Respir Cell Mol Biol 2001, 24:210-217

25. Supinski GS, Callahan LA: Diaphragmatic free radical generation increases in an animal model of heart failure. J Appl Physiol 2005, 99:1078-1084.

26. Li X, Moody MR, Engel D, Walker S, Clubb FJ Jr, Sivasubramanian N, Mann DL, Reid MB: Cardiac-specific overexpression of tumor necrosis factor-alpha causes oxidative stress and contractile dysfunction in mouse diaphragm. Circulation 2000, 102:1690-1696.

27. Hida W, Shindoh C, Satoh J, Sagara M, Kikuchi Y, Toyota T, Shirato K. $\mathrm{N}$-acetylcysteine inhibits loss of diaphragm function in streptozotocin-treated rats. Am J Respir Crit Care Med 1996, 153:1875-1879.

28. Supinski GS, Vanags J, Callahan LA: Eicosapentaenoic acid preserves diaphragm force generation following endotoxin administration. Crit Care 2010, 14:R35.

29. Supinski GS, Vanags J, Callahan LA: Effect of proteasome inhibitors on endotoxin-induced diaphragm dysfunction. Am J Physiol Lung Cell Mol Physiol 2009, 296:L994-L1001.

30. Supinski GS, Wang W, Callahan LA: Caspase and calpain activation both contribute to sepsis-induced diaphragmatic weakness. J App/ Physiol 2009, 107:1389-1396.

31. Close RI: Dynamic properties of mammalian skeletal muscles. Physio/ Rev 1972, 52:129-197.

32. Callahan LA, She ZW, Nosek TM: Superoxide, hydroxyl radical, and hydrogen peroxide effects on single-diaphragm fiber contractile apparatus. J App/ Physiol 2001, 90:45-54.

33. Supinski G, Nethery D, Nosek TM, Callahan LA, Stofan D, DiMarco A: Endotoxin administration alters the force vs. pCa relationship of skeletal muscle fibers. Am J Physiol Regul Integr Comp Physiol 2000, 278:R891-R896.

34. Supinski G, Stofan D, Callahan LA, Nethery D, Nosek TM, DiMarco A: Peroxynitrite induces contractile dysfunction and lipid peroxidation in the diaphragm. J Appl Physiol 1999, 87:783-791.

35. Geiger PC, Cody MJ, Macken RL, Sieck GC: Maximum specific force depends on myosin heavy chain content in rat diaphragm muscle fibers. J Appl Physiol (1985) 2000, 89:695-703.

36. Eddinger TJ, Moss RL: Mechanical properties of skinned single fibers of identified types from rat diaphragm. Am J Physiol 1987, 253:C210-C218.

37. Mantilla CB, Sieck GC: Impact of diaphragm muscle fiber atrophy on neuromotor control. Respir Physiol Neurobiol 2013, 189:411-418

38. Zergeroglu MA, McKenzie MJ, Shanely RA, Van Gammeren D, DeRuisseau KC, Powers SK: Mechanical ventilation-induced oxidative stress in the diaphragm. J Appl Physiol 2003, 95:1116-1124.

39. Barreiro E, Gea J, Di Falco M, Kriazhev L, James S, Hussain SN: Protein carbonyl formation in the diaphragm. Am J Respir Cell Mol Biol 2005, 32:9-17.

40. Salvi N, Guellich A, Michelet P, Demoule A, Le Guen M, Renou L, Bonne G, Riou B, Langeron O, Coirault C: Upregulation of PPARbeta/delta is associated with structural and functional changes in the type I diabetes rat diaphragm. PLoS One 2010, 5:e11494.

41. Brotto M, Brotto L, Jin JP, Nosek TM, Romani A: Temporal adaptive changes in contractility and fatigability of diaphragm muscles from streptozotocin-diabetic rats. J Biomed Biotechnol 2010, 2010:931903.

42. Sheikh-Ali M, Sultan S, Alamir AR, Haas MJ, Mooradian AD: Effects of antioxidants on glucose-induced oxidative stress and endoplasmic reticulum stress in endothelial cells. Diabetes Res Clin Pract 2010, 87:161-166

43. Fatehi-Hassanabad Z, Chan CB, Furman BL: Reactive oxygen species and endothelial function in diabetes. Eur J Pharmacol 2010, 636:8-17.

44. San Martin A, Foncea R, Laurindo FR, Ebensperger R, Griendling KK, Leighton F: Nox1-based NADPH oxidase-derived superoxide is required for VSMC activation by advanced glycation end-products. Free Radic Biol Med 2007, 42:1671-1679.

45. Nishikawa T, Edelstein D, Brownlee M: The missing link: a single unifying mechanism for diabetic complications. Kidney Int Supp/ 2000, 77:S26-S30.

46. Nishikawa T, Edelstein D, Du XL, Yamagishi S, Matsumura T, Kaneda Y, Yorek MA Beebe D, Oates PJ, Hammes HP, Giardino I, Brownlee M: Normalizing mitochondrial superoxide production blocks three pathways of hyperglycaemic damage. Nature 2000, 404:787-790.
47. Powers SK, Ji LL, Kavazis AN, Jackson MJ: Reactive oxygen species: impact on skeletal muscle. Compr Physiol 2011, 1:941-969.

48. Jackson MJ: Control of reactive oxygen species production in contracting skeletal muscle. Antioxid Redox Signal 2011, 15:2477-2486.

49. Sakellariou GK, Vasilaki A, Palomero J, Kayani A, Zibrik L, McArdle A, Jackson MJ: Studies of mitochondrial and nonmitochondrial sources implicate nicotinamide adenine dinucleotide phosphate oxidase(s) in the increased skeletal muscle superoxide generation that occurs during contractile activity. Antioxid Redox Signal 2013, 18:603-621.

50. Supinski GS, Callahan LA: Free radical-mediated skeletal muscle dysfunction in inflammatory conditions. J App/ Physiol 2007, 102:2056-2063.

51. Supinski G: Free radical induced respiratory muscle dysfunction. Mol Cell Biochem 1998, 179:99-110.

52. Supinski GS, Callahan LA: Double-stranded RNA-dependent protein kinase activation modulates endotoxin-induced diaphragm weakness. J Appl Physiol 2011, 110:199-205.

53. Supinski GS, Ji XY, Callahan LA: p38 Mitogen-activated protein kinase modulates endotoxin-induced diaphragm caspase activation. Am J Respir Cell Mol Biol 2010, 43:121-127.

54. Supinski GS, Ji X, Callahan LA: The JNK MAP kinase pathway contributes to the development of endotoxin-induced diaphragm caspase activation. Am J Physiol Regul Integr Comp Physiol 2009, 297:R825-R834.

55. Supinski GS, Ji X, Wang W, Callahan LA: The extrinsic caspase pathway modulates endotoxin-induced diaphragm contractile dysfunction. J Appl Physiol 2007, 102:1649-1657.

56. Supinski GS, Callahan LA: Caspase activation contributes to endotoxin-induced diaphragm weakness. J Appl Physiol 2006, 100:1770-1777.

57. Smuder AJ, Kavazis AN, Hudson MB, Nelson WB, Powers SK: Oxidation enhances myofibrillar protein degradation via calpain and caspase-3. Free Radic Biol Med 2010, 49:1152-1160.

58. Whidden MA, Smuder AJ, Wu M, Hudson MB, Nelson WB, Powers SK: Oxidative stress is required for mechanical ventilation-induced protease activation in the diaphragm. J App/ Physiol 2010, 108:1376-1382.

59. Levine S, Nguyen T, Taylor N, Friscia ME, Budak MT, Rothenberg P, Zhu J, Sachdeva R, Sonnad S, Kaiser LR, Rubinstein NA, Powers SK, Shrager JB: Rapid disuse atrophy of diaphragm fibers in mechanically ventilated humans. N Engl J Med 2008, 358:1327-1335.

60. McClung JM, Kavazis AN, DeRuisseau KC, Falk DJ, Deering MA, Lee Y, Sugiura T, Powers SK: Caspase-3 regulation of diaphragm myonuclear domain during mechanical ventilation-induced atrophy. Am J Respir Crit Care Med 2007, 175:150-159

61. Nelson WB, Smuder AJ, Hudson MB, Talbert EE, Powers SK: Cross-talk between the calpain and caspase- 3 proteolytic systems in the diaphragm during prolonged mechanical ventilation. Crit Care Med 2012, 40:1857-1863.

62. Shanely RA, Zergeroglu MA, Lennon SL, Sugiura T, Yimlamai T, Enns D, Belcastro A, Powers SK: Mechanical ventilation-induced diaphragmatic atrophy is associated with oxidative injury and increased proteolytic activity. Am J Respir Crit Care Med 2002, 166:1369-1374.

63. Supinski GS, Wang L, Callahan LA: Effects of active caspase on contractile protein function and structure. Am J Respir Crit Care Med 2009, 179:A4188.

64. Communal C, Sumandea M, de Tombe P, Narula J, Solaro RJ, Hajjar RJ: Functional consequences of caspase activation in cardiac myocytes. Proc Natl Acad Sci U S A 2002, 99:6252-6256.

65. Lametsch R, Roepstorff P, Moller HS, Bendixen E: Identification of myofibrillar substrates for mu-calpain. Meat Sci 2004, 68:515-521.

66. Langouche L, Vander Perre S, Wouters PJ, D'Hoore A, Hansen TK, Van den Berghe G: Effect of intensive insulin therapy on insulin sensitivity in the critically ill. J Clin Endocrinol Metab 2007, 92:3890-3897.

67. Akbarzadeh A, Norouzian D, Mehrabi MR, Jamshidi S, Farhangi A, Verdi AA Mofidian SM, Rad BL: Induction of diabetes by Streptozotocin in rats. Indian J Clin Biochem 2007, 22:60-64.

68. Lenzen S: The mechanisms of alloxan- and streptozotocin-induced diabetes. Diabetologia 2008, 51:216-226.

69. Lin CY, Higginbotham DA, Judd RL, White BD: Central leptin increases insulin sensitivity in streptozotocin-induced diabetic rats. Am J Physiol Endocrinol Metab 2002, 282:E1084-E1091.

70. Watanabe $Y$, Singamsetty S, Zou B, Guo L, Stefanovski D, Alonso LC, Garcia-Ocana A, O'Donnell CP, McVerry BJ: Exogenous glucose administration impairs glucose tolerance and pancreatic insulin secretion during acute sepsis in non-diabetic mice. PLoS One 2013, 8:e67716. 
71. Derde S, Vanhorebeek I, Ververs EJ, Vanhees I, Darras VM, Van Herck E, Larsson L, Van den Berghe G: Increasing intravenous glucose load in the presence of normoglycemia: effect on outcome and metabolism in critically ill rabbits. Crit Care Med 2010, 38:602-611.

72. Saha JK, Xia J, Engle SK, Chen YF, Glaesner W, Jakubowski JA: A model of controlled acute hyperglycemia in rats: effects of insulin and glucagon-like peptide-1 analog. J Pharmacol Exp Ther 2006, 316:1159-1164.

73. Mesotten D, Van den Berghe G: Glycemic targets and approaches to management of the patient with critical illness. Curr Diab Rep 2012, 12:101-107.

74. Finfer S, Liu B, Chittock DR, Norton R, Myburgh JA, McArthur C, Mitchell I, Foster D, Dhingra V, Henderson WR, Ronco JJ, Bellomo R, Cook D, McDonald E, Dodek P, Hebert PC, Heyland DK, Robinson BG: Hypoglycemia and risk of death in critically ill patients. N Eng/ J Med 2012, 367:1108-1118.

75. Finfer S, Wernerman J, Preiser JC, Cass T, Desaive T, Hovorka R, Joseph J, Kosiborod M, Krinsley J, Mackenzie I, Mesotten D, Schultz MJ, Scott MG, Slingerland R, Van den Berghe G, Van Herpe T: Clinical review: consensus recommendations on measurement of blood glucose and reporting glycemic control in critically ill adults. Crit Care 2013, 17:229.

doi:10.1186/cc13855

Cite this article as: Callahan and Supinski: Hyperglycemia-induced diaphragm weakness is mediated by oxidative stress. Critical Care 2014 18:R88.

\section{Submit your next manuscript to BioMed Central and take full advantage of:}

- Convenient online submission

- Thorough peer review

- No space constraints or color figure charges

- Immediate publication on acceptance

- Inclusion in PubMed, CAS, Scopus and Google Scholar

- Research which is freely available for redistribution 